\title{
The Edward Teller Medal Lecture: The Evolution Toward Indirect Drive and Two Decades of Progress Toward ICF Ignition and Burn
}

John Lindl

This paper was prepared for submittal to the 11th International Workshop on Laser Interaction and Related Plasma Phenomena Monterey, CA

October 25-29, 1993

December 1993

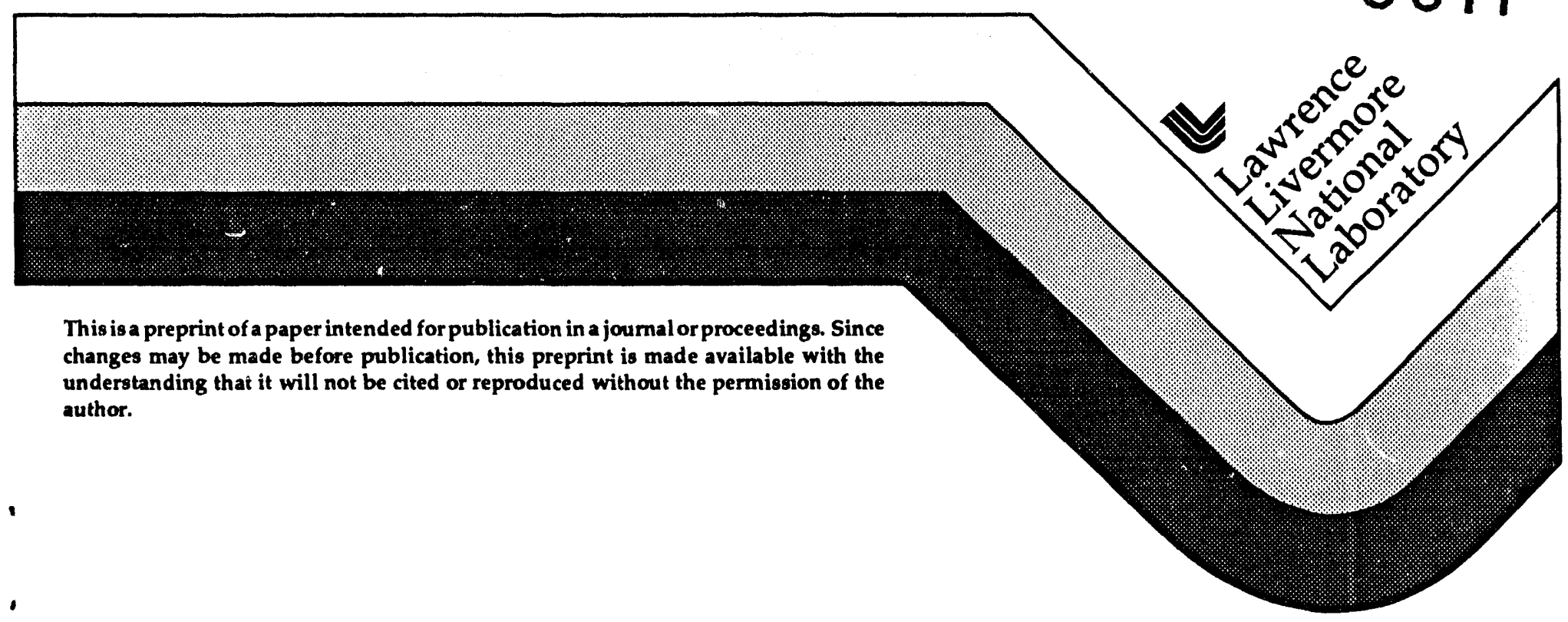

This is a preprint of a paper intended for publication in a journal or proceedings. Since changes may be made before publication, this preprint is made available with the understanding that it will not be cited or reproduced without the permission of the author.

\section{RECEIVED} MAR 02 1994

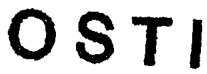




\section{DISCLAIMER}

This document was prepared as an account of work sponsored by an agency of the United States Government. Neither the United States Government nor the University of California nor any of their employess, makes any warranty, express or implied, or assumes any legal liability or responsibility for the accu racy, completeness, or usefulness of any information, apparatus, product, or process disclosed, or represents that its use would not infringe privately owned rights. Reference herein to any specific commercial products, process, or service by trade name, trademark, manufacturer, or otherwise, does not necessarily constitute or imply its endorsement, recommendation, or favoring by the United States Government or the University of California. The views and opinions of authors expressed herein do not necessarily state or reflect those of the United States Government or the University of California, and shall not be used for advertising or product endorsement purposes. 


\title{
THE EDWARD TELLER MEDAL LECTURE: THE EVOLUTION TOWARD INDIRECT DRIVE AND TWO DECADES OF PROGRESS TOWARD ICF IGNITION AND BURN
}

\author{
John D. Lindl \\ Lawrence Livermore National Laboratory \\ Livermore, California 94550 USA \\ Eleventh International Workshop on Laser Interaction \\ Monterey, California
}

In 1972, I joined the Livermore ICF Theory and Target Design group led by John Nuckolls, shortly after publication of John's seminal Nature article on ICF. 1 My primary role, working with others in the target design program including Mordy Rosen, Steve Haan, and Larry Suter, has been as a target designer and theorist who utilized the LASNEX code to perform numerical experiments, which along with analysis of laboratory and underground thermonuclear experiments allowed me to develop a series of models and physical insights which have been used to set the direction and priorities of the Livermore program.

I have had the good fortune of working with an outstanding team of scientisis who have established LLNL as the premier ICF laboratory in the world. John Emmett and the LLNL Laser Science team were responsible for developing a series of lasers from Janus to Nova which have given LLNL unequaled facilities. George Zimmerman and the LASNEX group developed the numerical models essential for projecting future performance and requirements as well as for designing and analyzing the experiments. Bill Kruer, Bruce Langdon and others in the plasma theory group developed the fundamental understanding of laser plasma interactions which have played such an important role in ICF. And a series of experiment program leaders including Mike Campbell and Joe Kilkenny and their laser experimental teams developed the experimental techniques and diagnostic capabilities which have allowed us to conduct increasingly complex and sophisticated experiments.

Since 1975, for reasons described below, the Livermore ICF Program has concentrated most of its effort on the Indirect Drive approach to ICF. In this approach, the driver energy, from laser beams or ion beams, is first absorbed within a high-z enclosure, a hohlraum, which surrounds the capsule. The material heated by the driver emits $x$-rays which drive the capsule implosion. 
Typically, $70-80 \%$ of the driver energy can be converted to $x$-rays. The optimal hohlraum geometry depends on the driver. Schematic hohlraums for a laser and heavy ion beam driver are shown in Fig. 1.

The target physics constraints on laser driven indirect drive ignition targets have been identified as shown in Fig. 2. Driver target coupling issues, which include laser absorption, $x$-ray conversion and transport, limit laser driven hohiraums to an $x$-ray intensity of about $10^{15} \mathrm{~W} / \mathrm{cm}^{2}$. This is primarily the result of laser driven parametric instabilities which result in scattering and production of high energy electrons which cause capsule preheat. Given the x-ray flux limitations, and the implosions velocity required for ignition, the flux onto the capsules must be sufficiently uniform to allow the capsules to converge a factor of 25-35. This convergence is defined as the ratio of the initial outer radius of the capsule to the compressed radius of the hot spot which ignites the fuel. For a capsule, to achieve convergences this large and remain nearly spherical, $x$-ray fluxes must be uniform to $1-2 \%$. This kind of uniformity in hohlraums requires a hohlraum which is large compared to the capsule. Hohlraum areas are typically 15-25 times that of the initial capsule area. Such a large area hohlraum limits hohlraum coupling efficiencies to $10-15 \%$. It should ultimately be possible to achieve a coupling efficiency of $20-25 \%$ through the use of optimal driver and hohlraum geometries.

Hydrodynamic instability places a limit of 25-35 on the ratio of shell radius $\mathrm{R}$ to shell thickness $\Delta \mathrm{R}$, as it implodes. As discussed below, the achievable implosion velocity, which is the primary determinant of the minimum size driver for ignition, is determined by a combination of the allowable capsule aspect ratio and the maximum achievable intensity.

Based on these constraints, the U.S. Department of Energy is considering building a National Ignition Facility (NIF) based on the Neodymium glass laser. This facility would be capable of delivering $1.8 \mathrm{MJ}$ of $0.35 \mathrm{~mm}$ laser light with a peak power of 500 TW. The gains calculated for this facility are shown in Fig. 3.

We are nearing completion of a two decade quest to develop the data and numerical modeling capabilities needed to accurately specify the requirements for ignition and high gain radiation driven ICF targets. Some of the highlights of this effort are listed in Fig. 4. Throughout its history, research on indirect drive in the U.S. has been largely classified. A proposed DOE declassification should go a long way toward achieving a long time goal of Edward Teller and most of the 
research scientists in the field for more openness and international cooperation in ICF.

I have started the chronology in Fig. 4 with the publication of Nuckolls Nature paper, partly because that is when I joined the LLNL ICF Program, but also because it occurred approximately at the time when laser technology, diagnostic development and numerical modeling were becoming sufficiently mature that an expanded ICF program could begin to evaluate the limits and requirements for success of ICF. Nuckolls paper was based on the direct drive implosion of bare drops or shells of DT. But as indicated, by 1975 LLNL had shifted to radiation driven implosions. Before following the chronology in Fig. 4 further, I want to describe the series of developments which led to this change in direction.

Figure 5 shows Nuckolls original gain curves as a function of fuel compression. These curves predict that targets driven by lasers as small as $1 \mathrm{~kJ}$ could achieve target gains greater than unity if sufficient compression is achieved. Drivers of about $1 \mathrm{MJ}$ were predicted to be required for high gain. Although today's estimates of the driver size required for high gain have not changed significantly, we now believe that about a $1 \mathrm{MJ}$ driver will be required to achieve ignition as well.

Why has the ignition threshold increased by such a large factor while the requirements for high gain have remained fairly constant? This apparent disparity is explained by the extreme sensitivity of the ignition threshold to the implosion velocity which can be achieved in near spherical implosions in which the fuel remains nearly Fermi-degenerate. A simple model for an isobaric implosion ${ }^{2}$ would predict that the required energy would scale as $\beta^{3} V^{-10}$ where $\mathrm{V}$ is the implosion veloci, 'nd $\beta$ is the ratio of the pressure in the fuel to the Fermi pressure. Detailed numerical calculations predict that this dependency is approximately reduced to:

$$
E_{\text {capsule }}(M J)=1 / 2\left(\frac{0.05}{\eta_{\text {hydro }}}\right) \beta^{3 / 2}(V / 3)^{-5}
$$

where $\eta_{\text {hydro }}$ is the hydrodynamic efficiency and $V$ is in units of $10^{7} \mathrm{~cm} / \mathrm{sec}$. The reduction in the velocity dependence from an ideal isobaric model is the result of several factors including an increase in the required hot spot temperature as the target size decreases, and an increase in the fractional mass in the hot spot which 
self consistently occurs during the compression and results in a reduced compression and hot spot coupling efficiency.

The strong dependence of the minimum energy on the achievable implosion velocity means that there is only a factor of about 4 in the implosion velocity required to go from a minimum energy of about $1 \mathrm{MJ}$ to a minimum energy of $1 \mathrm{~kJ}$, as shown in Fig. 5 . The range of velocities indicated depends on the ignition margin required to overcome the effects of mix during the process of assembling the hot spot.

The dependence of gain on implosion velocity is much weaker. To zero order, the reduction in gain with reduction in target size, or increase in implosion velocity, occurs primarily because less mass is imploded per joule of energy coupled to the target. For equal burn efficiency, the gain would scale as $\mathrm{V}^{-2}$ so that there would be about an order of magnitude less gain at $1 \mathrm{~kJ}$ than at $1 \mathrm{MJ}$, as shown in the curves of Nuckolls. Once targets with a DT pusher ignite, they are expected to burn as calculated. In practice, compressions achieved in self consistent implosions are lower than the optimal indicated in Fig. 4 and the gain is a stronger function energy.

The targets being designed for the proposed NIF require velocities of $3-4 \times 10^{7} \mathrm{~cm} / \mathrm{sec}$. We now believe that implosion velocities are limited to values near this range because of the intimate coupling between the implosion velocity and the physics governing the hydrodynamic instability of an ICF implosion and the maximum intensity allowed by efficient laser plasma coupling. Higher implosion velocities are possible in certain types of high entropy implosions such as exploding pushers capsules but these targets do not scale to high gain.

The dispersion relation for the Rayleigh-Taylor instability used by Nuckolls in 1972 was one attributed to Leith based on a model of fire polishing during the ablation process:

$$
\gamma^{2}=k a-k^{2} \frac{P_{a}}{\rho}=k a(1-k \Delta R)
$$

where $P_{a}$ is the ablation pressure, $k$ is the wave number, and $\Delta R$ is the shell thickness. This dispersion relation predicts that all wavelengths shorter than $2 \pi \Delta R$ are stabilized and that the maximum number of e-foldings is approximately: 


$$
n_{\max }=\int \gamma_{\max } d t \approx \frac{1}{2} \sqrt{\frac{R}{\Delta R}}
$$

for constant acceleration and $1 / 2 a t^{2}=R / 2$. The shell aspect ratio $R / \Delta R$ can be related to the implosion velocity, the shell adiabat and the laser intensity and laser wavelength by integrating the rocket equation for a directly driven laser implosion ${ }^{3}$ :

$$
\frac{R}{\Delta R}=0.7 \frac{V^{2}}{V_{e x} V_{a b l}}=\frac{60(V / 3)^{2}}{\beta^{\frac{3}{5}}\left(I_{15} / \lambda\right)^{\frac{4}{15}}}
$$

where $I_{15}$ is the laser intensity in units of $10^{15} \mathrm{~W} / \mathrm{cm}^{2}$ and $\lambda$ is the laser wavelength in microns. $V_{A} \equiv \dot{m} / \rho$ is the ablation velocity, $\dot{m}$ is the mass ablation rate and $\rho$ is the peak density in the shell. $V_{e x}$ is the exhaust velocity from the rocket equation:

$$
V=-\frac{P}{\dot{m}} \ln \left(m / m_{o}\right) \equiv-V_{\text {ex }} \ln \left(m / m_{o}\right)
$$

$m$

where $m_{0}$ is the initial shell mass and $m$ is the final shell mass. $P$ is the ablation pressure driving the implosion. Using the definitions of $V_{e x}$ and $V_{a b l}$, Eq. (4) can also be written:

$$
\frac{R}{\Delta R} \approx 3 / 4 \frac{\rho V^{2}}{P}
$$

In this form it is clear that the aspect ratio can be simply obtained by setting the energy in a shell of thickness $\Delta R$ equal to the PdV work that can done during an implosion over half the total volume of the shell.

Equations (1), (3), and (4) can be combined to obtain:

$$
E_{\text {capsule }}(M J)=1 / 2 \beta^{3 / 2}(V / 3)^{-5} \approx 1 / 2\left(\frac{n_{\max }}{10 / 3}\right)^{-5} I_{15}^{-2 / 3}
$$

where a typical direct drive coupling efficiency of $5 \%$ into the compressed fuel is assumed, very little margin is allowed for mix during assembly of the hot spot, 
and $\lambda=1 / 3 \mu \mathrm{m}$ is chosen for the laser wavelength. This transforms the minimum driver energy for direct drive into a relationship which depends only on the maximum allowed growth of hydrodynamic instabilities and the allowed laser intensity. If we let the maximum number of e-foldings equal 6 , we get:

$$
E_{\text {capsule }}(K J)=26 I_{15}^{-2 / 3}
$$

If we allow a maximum intensity of $10^{17} \mathrm{~W} / \mathrm{cm}^{2}$, then the minimum driver energy is $1 \mathrm{~kJ}$. In 1972, computers and numerical models were just becoming powerful enough to begin doing detailed evaluation of the effects of hydrodynamic instability and the limits that laser plasma instabilities would place on the allowable intensity. Over the next few years we learned that laser intensities would be limited to $10^{14}$ to a few times $10^{15} \mathrm{~W} / \mathrm{cm}^{2}$ depending on the laser wavelength. Numerical calculations provided most of the guidance for the growth of Rayleigh-Taylor instability until quantitative data became available in the late 1980's and the early 1990's.

By 1974, numerical calculations by Bill Mead and me, 4 using the LASNEX code, indicated that direct drive capsules would have much higher instability growth rates than indicated by Eq. (2). In addition, experiments had begun using Neodymium glass lasers which indicated that reduced absorption and hot electron production would severely degrade direct drive implosions at the high intensities required for ignition with lasers in the 1-100 kJ range. The laser beam quality was also much worse than could be tolerated for the implosion uniformity required for direct drive.

In hind sight, it is possible to write down a set of equations which quantify the limitations imposed on direct drive by these constraints. In 1985, Takabe et al., 5 wrote down a dispersion relation for direct drive Rayleigh-Taylor instability. Takabe's formula

$$
\gamma=0.9 \sqrt{k a}-\beta k V_{A} \quad \text { where } \beta=3-4
$$

has a far weaker form of ablation stabilization than that given by Eq. (2). Takabe's formula is obtained from a series of numerical calculations with very small density gradients at the ablation front. This formula can be modified 6 to account for density gradients which can result in significant stabilization in certain types of direct drive implosions: 


$$
\gamma=\sqrt{\frac{k a}{1+k L}}-3 k V_{A}
$$

where $L$ is the density gradient scale length and $\beta=3$ has been used. This density gradient stabilization correction was first proposed by Lelevier 7 based on a suggestion by Teller. Experiments ${ }^{8}$ have now been carried out which agree with the numerical simulations and are in substantial agreement with Eq. (9) although the coefficients multiplying $\mathrm{L}$ and $\mathrm{V}_{\mathrm{A}}$ are not universal. These experiments, having a variety of wavelength, initial amplitudes, and laser beam quality, have been carried out using two beams of the Nova laser as shown schematically in Fig. 6. Shown in Fig. 7 are the amplitude versus time for a variety of wavelengths with an initial amplitude of $1 \mu \mathrm{m}$. Also shown are the amplitudes versus time of the various harmonics which grow up as the shape of applied perturbation is distorted by nonlinear effects.

Integrating Eq. (8), the maximum number of e-foldings is given by:

$$
n=\int \gamma d t=\sqrt{\frac{l}{1+0.1 l \frac{\Delta R}{R}}}-3 l \frac{\Delta R}{R}\left(1-m / m_{o}\right)
$$

where $\ell=k / R$ is Legendre polynomial mode number. A value for the density gradient scale length $\mathrm{L}=0.1 \Delta \mathrm{R}$ has been chosen. This is near the maximum that has been achieved in calculations of direct drive implosions designed to minimize Rayleigh-Taylor instability. The quantity $\mathrm{m} / \mathrm{m}_{\mathrm{o}}$ comes from the rocket equation, Eq. (5) above.

For direct drive, over the range of velocities and intensities of interest to ICF,

$$
\left(1-m / m_{o}\right) \approx 0.2(V / 3) I_{15}^{-0.3}
$$

Using Eqs. (4) and (11) in Eq. (10), the maximum number of e-foldings is then given approximately by:

$$
n_{\max } \approx 8.5 \beta^{-2 / 5}(V / 3)^{1.4} I_{15}^{-1 / 15}
$$


again choosing $\lambda=1 / 3 \mu \mathrm{m}$ as the laser wavelength. Combining this equation with Eq. (1) for a 5\% efficient coupling between driver and imploding fuel, the required driver energy becomes:

$$
E_{\text {driver }}(M J) \approx 1 / 2\left(n_{\max } / 8.5\right)^{-25 / 7} I_{15}^{-1 / 4}
$$

Eq. (13) has a much higher ignition threshold, and a much weaker dependence on laser intensity than Eq. (7). If we allow a maximum amplification of 1000 (6.9 e-foldings) then we have:

$$
E_{\text {driver }}(M J) \approx 1.0 I_{15}^{-1 / 4}
$$

This, result, which allows little margin for degradation due to mix or asymmetry during assembly of the hot spot, is consistent with recent calculations ${ }^{9}$ at the University of Rochester as shown in Fig. 8.

A great deal of progress has been made toward solving the irradiation uniformity problem for direct drive. A series of clever optical inventions both in the U.S. and Japan 10-12 has traded off laser beam coherence for laser beam uniformity so that it is now possible to obtain beams which are uniform to a few percent. The overlap of a large number of beams and further optical innovation should allow the achievement of the $<1 / 2 \%$ nonuniformity estimated to be required for direct drive. Further optimization of density gradient stabilization effects may allow for a reduction in the direct drive threshold below the $1 \mathrm{MJ}$ estimated above. In the U. S., the Omega Upgrade laser under construction at the University of Rochester is designed to answer these questions, and the NIF conceptual design will be consistent with the addition of a direct drive option. In Japan, the Gekko XII laser is being upgraded for the same purposes.

After the 1974 direct drive hydrodynamic instability calculations, I began an effort to develop high gain radiation implosions. A primary virtue of radiation driven implosions is the fact that they have much higher ablation rates and thicker shells which make control of the Rayleigh-Taylor instability more feasible. In addition, because the laser beams are absorbed far from the capsule, as shown in Fig. 1, radiation driven implosions are unaffected by small scale laser beam nonuniformities. Also because of solid angle effects, and the fact that radiation driven capsules are thicker than directly driven capsules, indirect drive targets are less sensitive to the effects of hot electrons produced by laser driven 
parametric instabilities. A disadvantage of indirect drive for lasers, compared to direct drive, is the longer scalelength of plasma traversed by the laser as it propagates from the laser entrance hole to the hohlraum wall.

For indirect drive, the capsules and such issues as radiation transport, and hohlraum wall loss are essentially independent of the driver. Hence many of the results learned with lasers carry over to other drivers such as heavy ion beams. This synergism is particularly important for heavy ion beams drivers. Because of their efficiency, durability and high rep rate capability, these drivers are considered prime candidates for an Inertial Fusion Energy application. However, the research required to define the characteristics of a heavy ion beam driver that could reach the beam intensities required for ICF experiments is still incomplete. Indirect drive laser experiments provide a key element of the data base required to insure that heavy ion beam driven targets will work when the accelerators are available.

In 1975, I showed that it is possible, with proper design, to achieve high gain with radiation driven targets such as those in Fig 1 . These targets are very similar to direct drive targets, except that the choice of ablator material must be properly matched to the $x$-ray drive spectrum in order to insure that the fuel can be kept in a near Fermi degenerate state. From one point of view, soft $x$-ray driven implosions could be considered as being driven by a very short wavelength, very broad band laser. LASNEX calculations in 1975 showed a dramatic reduction in growth compared to direct drive. The dispersion relation which I obtained from these simulations is:

$$
\gamma=\sqrt{\frac{k a}{1+k L}}-k V_{A}
$$

and

$$
n=\int \gamma d t \approx \sqrt{\frac{l}{1+.1 l \frac{\Delta R}{R}}}-0.8 l \frac{\Delta R}{R}
$$

Eq. (15) which I wrote down in 1982 is essentially the same as for direct drive, except the $k V_{A}$ term is multiplied by 1 instead of 3 . Even with the lower coefficient multiplying the ablation term, the much higher ablation rates and the 
resultant thicker shells and larger density scale length result in lower growth for indirect drive under conditions required for ICF. Ablation stabilization can be understood as a simple convective effect due to the fact that Rayleigh-Taylor modes are surface modes. In the absence of ablation, the amplitude $\eta$ of a Rayleigh-Taylor mode is given by:

$$
\eta=e^{y_{0} t} e^{-k_{0}}
$$

where $\gamma_{0}$ is the growth rate in the absence of ablation and $x_{0}$ is position measured relative to the initial surface of the shell. In an ablating shell, the only material that matters to the implosion is the material inside of the ablation front. The ablated material disappears beyond the sonic horizon of the shell and no longer affects the implosion. When distance into the shell is referenced relative to the ablation front $X_{A}$, Eq. (17) becomes:

$$
\eta=e^{\gamma_{0} t} e^{-\left(k x_{0}+k V_{A} t\right)}=e^{\left(r_{0}-k V_{A}\right) t} e^{-k x_{A}}
$$

and there is an effective reduction in growth. In this model with a uniform density shell, it makes sense to define the ablations velocity relative to the peak density, as was done earlier. However, in an actual experiment, the RayleighTaylor mode will not necessarily be located near peak density. The coefficient multiplying $V_{A}$ varies by a factor of about 2 in numerical simulations and this could be due to variations in the position of the modes relative to the peak density. The factor of 2-3 difference between direct drive and indirect drive could also be due to this effect.

Nova Experiments ${ }^{13}$ and calculations for indirect drive Rayleigh-Taylor instability are in substantial agreement and are consistent with Eq. (15). Figure 9 shows a typical setup for these experiments. Data are obtained by looking at an $x$-ray backlighter through a sample placed near the hohlraum wall. By looking face-on through a perturbed sample using either an $x$-ray framing camera or an $x$-ray streak camera, the flow of material from thin to thick regions can be observed as an increase in the contrast in $x$-ray transmission through the sample. Representative data and calculations are shown in the upper right hand corner of Fig. 9. By looking edge-on to a perturbed sample, the shape of the perturbations can be recorded by using an x-ray framing camera. Representative data and calculations are shown as the middle two images in Fig. 9. By using an x-ray 
streak camera and looking edge-on, the sample position versus time can be recorded. Representative data and calculations are shown in the bottom two images in Fig. 9.

By integrating the rocket equation for indirect drive, we can obtain a relation between the shell aspect ratio, the implosion velocity and the ablation velocity:

$$
V / 3 \approx 1 / 2 \frac{R}{\Delta R} \frac{V_{A}}{3} \approx \frac{R / \Delta R}{22} \beta^{3 / 5} I_{15}^{9 / 40}
$$

If we limit the maximum number of e-foldings to about 6 , then Eq. (16) implies that $R / \Delta R=30$. Using Eq. (1) with a $15 \%$ hydro efficiency we obtain for the capsule energy:

$$
E_{\text {capsule }}(K J) \approx 35 \beta^{-3 / 2} I_{15}^{-9 / 8}
$$

The maximum tolerable capsule aspect ratio depends on the capsule surface finish and the spectral distribution of perturbations. Central to the ICF strategy for igniting the minimum size capsule is keeping growth small enough that these hydrodynamic ins.abilities remain in the linear or only weakly non-linear regime. ${ }^{14}$ In this regime, mode coupling is small and the performance of capsules can be predicted by taking an RMS sum of the effects of the whole spectrum of initial perturbations either initially present on a capsule or impressed during the implosion process by such effects as intensity nonuniformity. All of these considerations result in an In-flight capsule aspect ratio of about 30 .

Equation (20) gives capsule energies very close to the projections in Nuckolls 1972 paper, and in fact scales more favorably with intensity. However, there is a price to be paid in hohlraums to produce $x$-rays, and to transport them symmetrically to a capsule. Further, there are limits to the achievable $x$-ray intensity. With these considerations, the minimum driver energy for indirect drive is also approximately 0.5-1 MJ. The larger energy allows for the effects of hot and cold fuel mixing together while the hot spot is being assembled. Hence the currently projected minimum energy for ignition and burn propagation are 
quite similar for both direct and indirect drive. The proposed National Ignition Facility is being designed to be consistent with pursuing both approaches.

However, because of relaxed beam quality requirements and reduced sensitivity to Rayleigh-Taylor instability, it has been possible over the past two decades to make more rapid progress toward obtaining the radiation drive data base required to quantitatively specify the driver requirements for ignition. In the U.S., a comparable data base for direct drive will not be available until completion of the experiments planned for the Omega Upgrade, some time after the end of the decade.

In 1976, I designed targets for the first laser driven radiation implosions. Targets based on these designs, which required about 100 joules of $1 \mu \mathrm{m}$ laser light, were fielded on the Cyclops laser at LLNL in the spring of 1976 and worked essentially as calculated. These results made us extremely optimistic about radiation drive, resulted in a shift of the Shiva laser from a uniform illumination scheme to a two sided irradiation scheme for direct drive, and formed the basis for the early optimism about the possibilities for achieving breakeven on a $200 \mathrm{~kJ}$ twenty beam Nova laser.

However, as we tried to achieve higher drive temperatures for high density implosions and higher yields, parametric instabilities generated high levels of energetic electrons. Coupling difficulties hampered progress in the LLNL program on both the Argus and Shiva laser as we worked to achieve a $100 \mathrm{X}$ liquid DT fuel density implosion goal.

In the initial Cyclops hohlraum experiments, the presence of high energy electrons, which we later determined were produced by Stimulated Raman Scattering, showed up as noise in the neutron detectors. We tested three different size hohlraums. The smaller two had such a large high energy noise signal that they could not be used for implosions. So we did the implosion experiments in the larger lower temperature hohlraum which had low noise levels. We were later to find that laser plasma parametric instabilities strongly limit the hohlraum temperature that can be achieved with a given size and wavelength laser.

Because we lacked adequate models for certain key pieces of the physics, including NLTE atomic physics for the high-z hohlraum walls, and adequate understanding of the laser plasma interactions below critical density inside the hohlraum, we believed that absorption would be high in hohlraums for $1 \mu \mathrm{m}$ light and that conversion to $x$-rays would be very high. We fully expected to achieve 100X liquid density on the Argus laser and be able to go on to more 
aggressive implosions on Shiva. We did achieve implosions near 100X on Shiva but primarily spent the years on Shiva and Argus developing an understanding of the source and limitations imposed by hot electron production in hohlraums.

In 1978, based on an examination of the plasma conditions calculated for the Shiva hohlraums, and an improved understanding of Stimulated Raman Scattering developed by Bill Kruer and Bruce Langdon, I proposed a model for the limitations on hohlraum temperatures as a function of laser wavelength. This model predicted that we would be able to achieve the temperature required for high gain if the proposed Nova laser were built to produce the third harmonic of the neodymium glass laser by using non-linear conversion in KDP crystals. This became practical because of efficient conversion schemes initially devised by the University of Rochester ${ }^{15}$. The improved coupling in hohlraums was demonstrated at the $100 \mathrm{~J}$ level in a series of experiments by Mike Campbell on the Argus laser in 1980-81.

In 1979, I used these estimates of the achievable radiation temperatures and an estimate of the hohlraum coupling efficiency which could be achieved consistent with the required implosion symmetry to estimate the single shell target gains shown in Fig. 10. These gains were very similar to those now estimated for the National Ignition Facility.

In 1981, when it became clear that ignition would not be achieved on the Nova laser, I devised a strategy for obtaining the data base which would be required for ignition on a future facility. This strategy tests the physics of high gain targets by using a series of Nova experiments on targets which are as close as possible to being "Hydrodynamically Equivalent Targets" (HET) and a series of underground experiments at much larger energy. This series of experiments would be the ICF equivalent of wind tunnel tests to provide the basis for the facility that would ultimately be required for ignition and high gain.

Since 1981, the LLNL ICF program has focused on carrying out the work needed to develop the quantitative modeling tools, diagnostics, and experimental techniques required to develop this physics basis. This strategy was endorsed by the Foster Review in 1981, along with the recommendation that Nova be a smaller 10 beam laser with $2 \omega$ and $3 \omega$ capability. These recommendations were implemented and Nova has proved to be an extremely successful facility. In addition, the Halite/Centurion program, which was a joint Livermore/Los Alamos program of underground experiments, put to rest fundamental questions about the basic feasibility of high gain. 
When John Nuckolls left the ICF Program in 1983 to assume leadership of the LLNL Physics department, I assumed responsibility for the ICF Theory and Target Design Program. In that year, the first two beams of Nova were constructed as a laser test bed and experimental facility called Novette which gave us our first multikilojoule experience with $2 \omega$ light. ICF experiments on this facility only lasted about three months but indicated that we were very likely to achieve our hohlraum temperature goals on Nova.

The Happer review by the NAS occurred just as Nova was being completed at the end of 1985 and little data was available. This review continued to endorse the HET approach but made the Halite/Centurion program the highest priority.

Between 1986 and 1990, LLNL made rapid progress under the ICF Program leadership of Erik Storm. During this period, the Experimental Program was led by Mike Campbell and I led the Theory and Target Design Program. Nova achieved its initial temperature goals soon after being activated. We had established this goal, based on my 1978 analysis, as the temperature which would be required for high gain with a 5-10 MJ laser. DOE labeled such a facility the Laboratory Microfusion Facility (LMF). Between 1986 and 1990, Nova experiments and quantitative modeling were carried out which showed symmeiry control, the expected benefits of pulse shaping, the first quantitative Rayleigh-Taylor instability experiments, and the radiation drive temperature scaling of implosions.

Also, under the leadership of Hank Shay, Steve Haan, and Tom Bernat at LLNL and the leadership of Tom McDonald at LANL, the Halite/Centurion experiments rapidly achieved their goals.

In 1990, I developed a model which quantified the dependence of the minimum driver energy on the achievable hohlraum temperature. Shortly after this, using the increased power and energy which had become available when Nova's laser glass was replaced with improved platinum free material, we were able to demonstrate the higher hohlraum temperatures that would be required for ignition and gain experiments with a 1-2 MJ laser. We proposed such a facility to DOE and the Koonin NAS committee which was in the process of reviewing the National ICF Program. Koonin's committee further refined the "hydrodynamic equivalence" effort by endorsing a series of specific goals in hohlraum and capsule physics which have become known as the Nova Technical Contract. Predicated on successful completion of these goals, this review 
recommended construction of a 1-2 MJ ignition facility based on a Neodymium glass laser as the next logical step for ICF.

The gains calculated for this facility, the NIF, are indicated in Fig. 3. Shown are gain curves at implosion velocities of 3 and $4 \times 10^{7} \mathrm{~cm} / \mathrm{sec}$, under the assumption of a fixed hohlraum coupling efficiency. At any given velocity, capsules below a certain energy, as discussed above, will fail to ignite because the hot spot will not achieve sufficient pr and temperature. The shaded bands correspond to a minimum cutoff energy which depends on hydrodynamic instability levels and capsule surface quality. The left-hand edge of each band corresponds to the gain for perfectly uniform implosions. The right-hand edge of each band corresponds to the gain for targets with surface finishes of 500-100 $\AA$. On Nova, we have demonstrated hohlraum drive temperatures consistent with a velocity of $4 \times 10^{7} \mathrm{~cm} / \mathrm{sec}$.

In the year following the 1990 NAS review, I took on responsibility for the overall target physics program and Mike Campbell became the ICF program leader as we worked toward meeting the laser technology and target physics goals endorsed by the NAS. As part of its conclusions, the Koonin committee recommended that Los Alamos become an integral part of the Nova physics program and that work has been jointly supported by LLNL and LANL since the end of 1990. A key element of the Nova program from 1991 to 1993 has been an extensive series of hohlraum symmetry experiments. A large number of people from LLNL and LANL participated in these experiments which formed the first major collaborative series on Nova. Allan Hauer from LANL was the lead experimentalist and Larry Suter from LLNL was primarily responsible for the analysis. For large hohlraum to capsule size ratios, hohlraums effectively smooth all but the longest wavelength perturbations. These long wavelengths must be eliminated by proper choice of laser or hohlraum geometry. As indicated in Fig. 11, the time integrated symmetry on Nova is controlled by varying the laser pointing or the hohlraum length. For an elongated hohlraum or for pointing which places the laser beams near the laser entrance hole, the average flux is pole high and the implosion is pancaked. As the beams are moved toward the midplane of the hohlraum, the flux becomes higher around the waist of the capsule which then implodes to a sausaged shape. In between these two extremes, the time average flux can be made uniform to better than $1 \%$, as required for high gain capsules. Figure 12 shows the ratio of the two axes of the imploded capsule, as the pointing is varied, for a $3: 1$ contrast, 2.2 ns pulse. A 
variety of pulse shapes have been tested and the experiments and calculations are in quite close agreement across the entire data base. Late in 1992, we carried out the first implosions which utilized a series of improvements to Nova's power balance and pointing accuracy. These improvements have allowed us to achieve extremely reproducible implosions as shown in Fig. 13. The shot to shot symmetry variations are less then $1 / 2 \%$ RMS, consistent with the requirements for the time averaged symmetry required for ignition targets.

In early 1993, DOE endcrsed the mission need for the National Ignition Facility and authorized development of a Conceptual Design Report (CDR) for the facility. The coming year is a critical period for the ICF Program as we work to complete the target physics and laser technology goals and the CDR. In the Target Physics Program, we have two primary goals. We are working to develop large size plasmas which mock up conditions in NIF scale hohlraums. Using these plasmas, we plan to quantify the laser capabilities which will be required to maintain efficient laser-plasma coupling at the hohlraum temperatures required for ignition on the NIF. In addition, we are working to complete a series of mix experiments with increasing hydrodynamic instability growth.

If all goes well, we hope to have DOE's endorsement for proceeding with the next step of the NIF and a recommendation to the Congress that the NIF be approved for a 1996 start. We would then be well on our way to completing the last leg toward demonstrating the feasibility of ICF. Demonstration of ignition and propagating burn would complete the physics basis for ICF and open up the path for applications of ICF including its utilization as a source for fusion power production.

\section{ACKNOWLEDGMENT}

Work performed under the auspices of the U.S. Department of Energy by the Lawrence Livermore National Laboratory under contract Number W-7405ENG-48. 


\section{REFERENCES:}

1. J.H. Nuckolls, L. Wood, A. Thiessen, and G.B. Zimmerman, "Laser Compression of Matter to Super-High Densities: Thermonuclear (CTR) Applications", Nature 239, 139 (1972)

2. Meyer-Ter-Vehn, Nucl. Fusion 16, 405 (1976)

3. J.D. Lindl, in "Fusion to Light Surfing", T. Katsouleas, ed., Addison-Wesley, Redwood City, Calif. (1991) p. 177

4. J.D. Lindl and W.C. Mead, "Two-Dimensional Simulation of Fluid Instability in Laser-Fusion Pellets", Phys. Rev. Lett. Vol. 34, Num. 20, (1975) p. 1273

5. H. Takabe, K. Mimo, L. Montierth, and R.L. Morse, Phys. Fluids 28,3676 (1985)

6. M. Tabak, D.H. Munro, and J.D. Lindl, Phys. Fluids B 2, 1007 (1990)

7. R. Lelevier, G. Lasher, and F. Bjorklund, "Effect of a Density Gradient on Taylor Instability", National Technical Information Service Document No. DE86002577, National Technical Information Service, Springfield, Virginia, 22161 (1955)

8. S.G. Glendinning et al,, "Laser Driven Planar Rayleigh-Taylor Instability Experiments, Phys. Rev. Lett. 69, 1201 (1992)

9. Unpublished presentation to the Inertial Confinement Fusion Advisory Committee, Aug 25-27, 1993

10. Y. Kato, K. Mima, N. Miyanaga, S. Arinaga, Y. Kitagawa, M. Nakatsuka, C. Yamanaka, Phys. Rev. Lett. 53, 1057 (1984)

11. S. Skupsky, R.W. Short, T. Kessler, R.S. Craxton, S. Letzring, and J.M. Soures, J. Appl. Phys. 66, 3456 (1989)

12. R. Lemburg, A. Schmitt, and S. Bodner, J. Appl. Phys, 62, 2680 (1987)

13. B.A. Remington, S.W. Haan, S.G. Glendinning, J.D. Kilkenny, D.H. Munro, R.J. Wallace, "Large Growth Rayleigh-Taylor Experiments Using Shaped Laser Pulses", Phys. Rev. Lett. 67, 3259 (1991)

14. S. Haan, "Weakly Nonlinear Hydrodynamic Instabilities in Inertial Fusion," Phys. Fluids B3, 2349 (1991)

15. W. Seka et al., Opt. Commun, 34, 469 (1980); R. S. Craxton, ibid., p. 474 
Capsule Implosion and burn physics as well as hohiraum energetics and $x$-ray transport are essentlally driver Independent

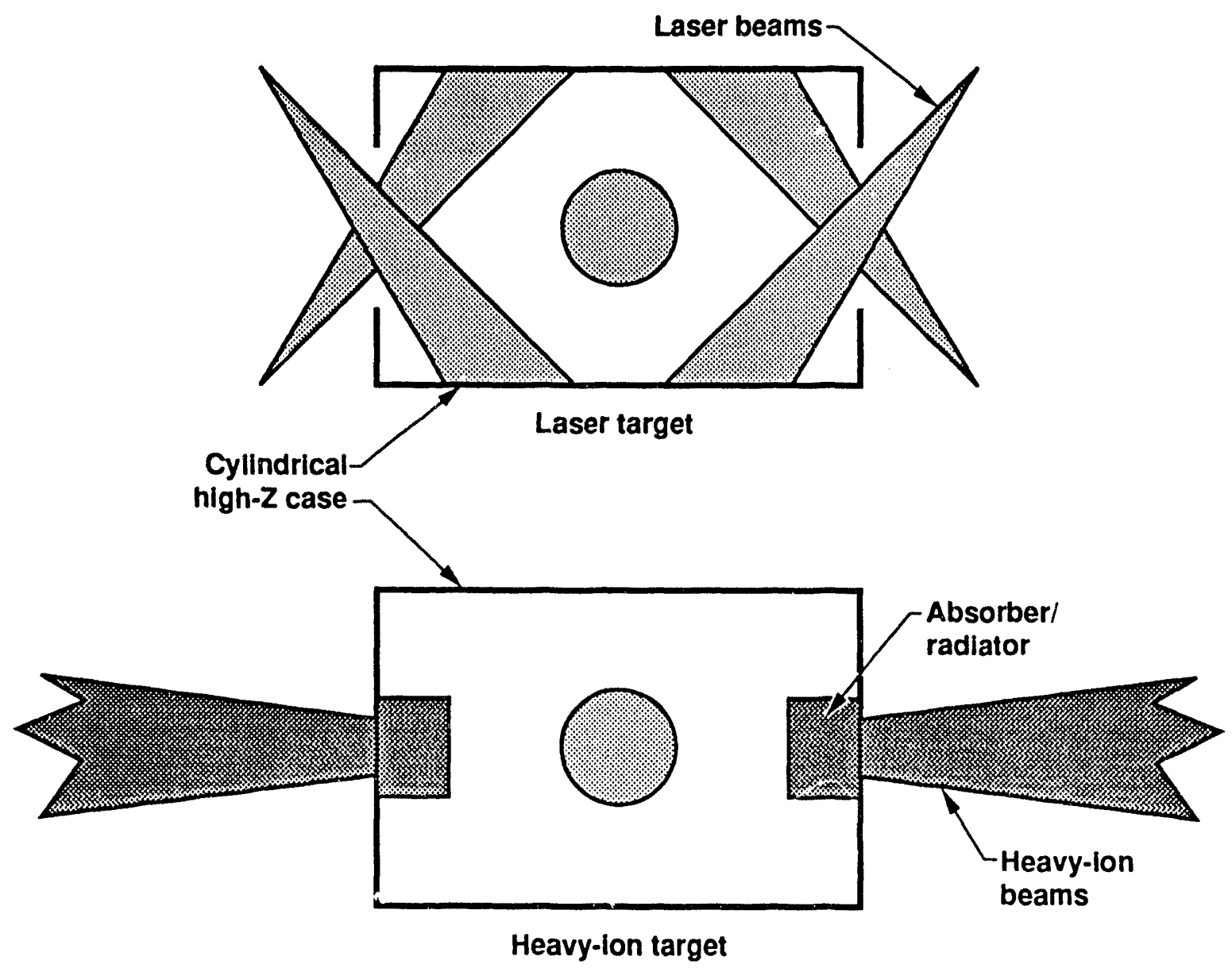

02-07.1192.3485 put

Fig. 1. The optimal hohlraum geometry for indirect drive depends on the driver.

12J0L/wh 
The Target Physics constraints on ICF ignition targets have been identified

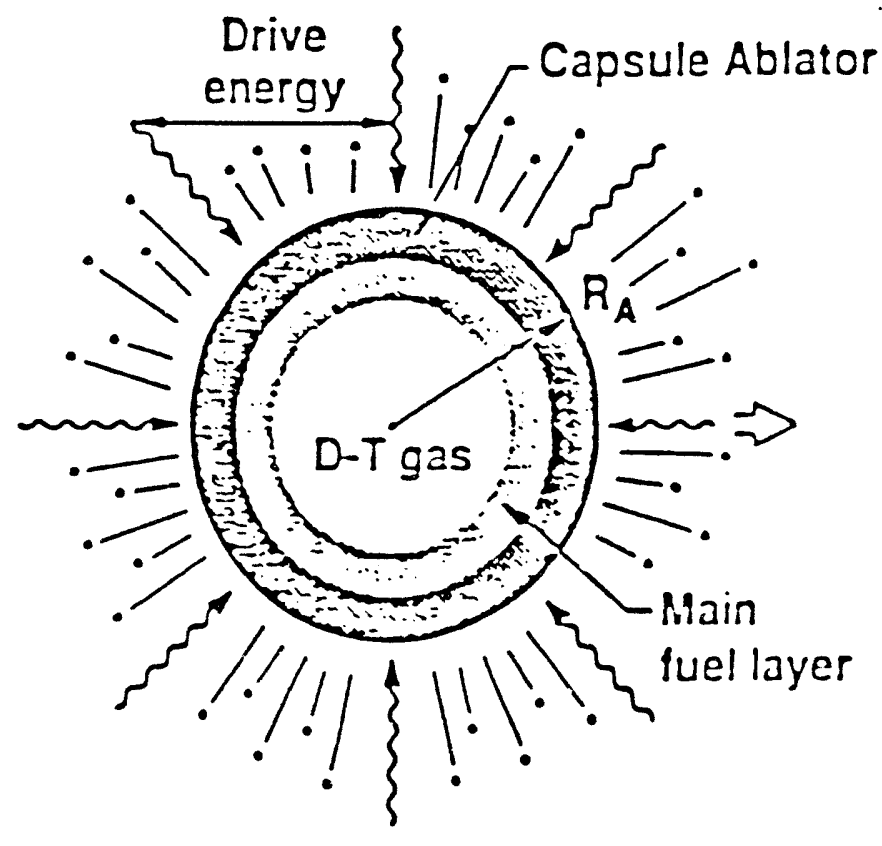

Driver-target coupling $\Rightarrow I r \leqslant 10^{15} \mathrm{w} / \mathrm{cm}^{2}$

- Absorption/preheat

- X-ray conversion

- Transportdrive
Symmetry: $\frac{R_{A}}{r_{H}}=\begin{gathered}\text { Convergence } \\ \text { ratio }\end{gathered}=25-35 \Rightarrow \begin{gathered}\text { Coupling } \\ \eta-10-15 \%\end{gathered}$
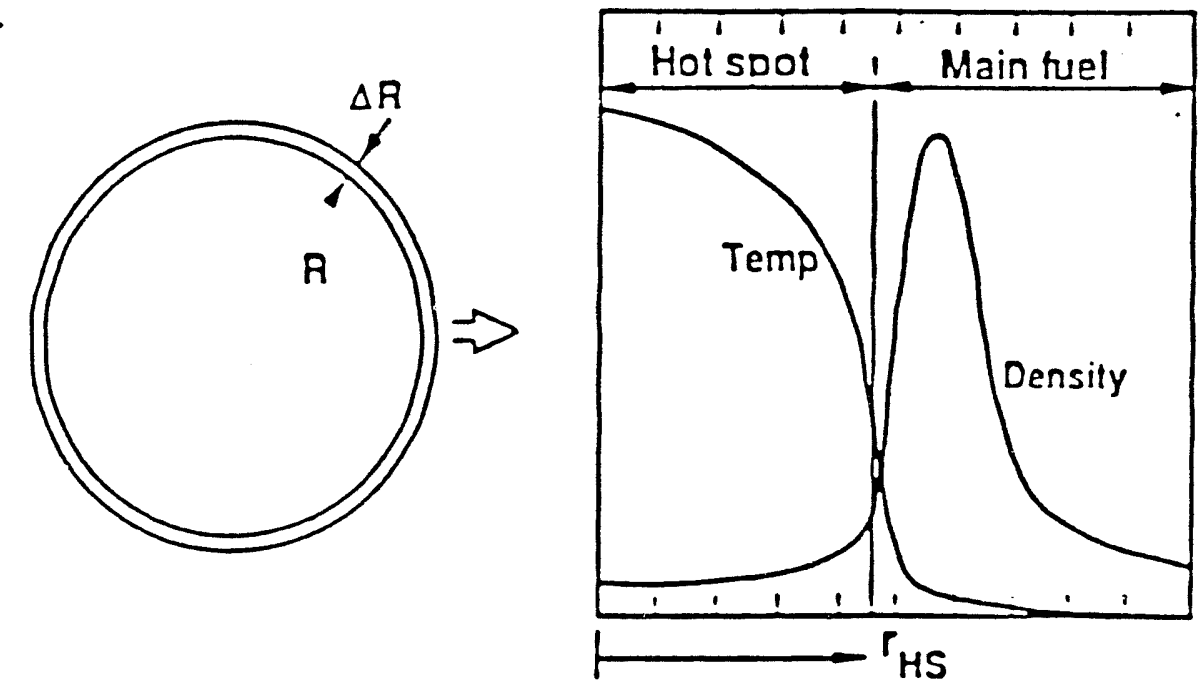

Stability: $\frac{r}{\Delta R}=\stackrel{\text { In-llight }}{\text { aspect ratio }}-25-35 \Rightarrow I_{r} \geqslant 4 \times 10^{14} \mathrm{w} / \mathrm{ca}^{2}$

Ignition:

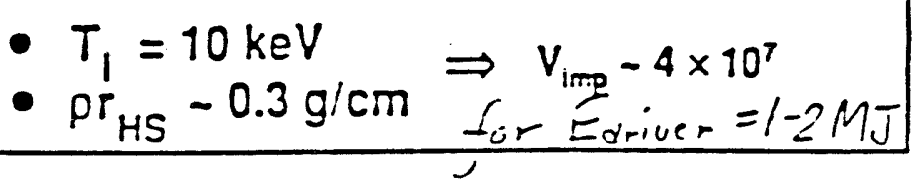

Must be compatible with pulse shaping for nearly fermi degenerate compression 


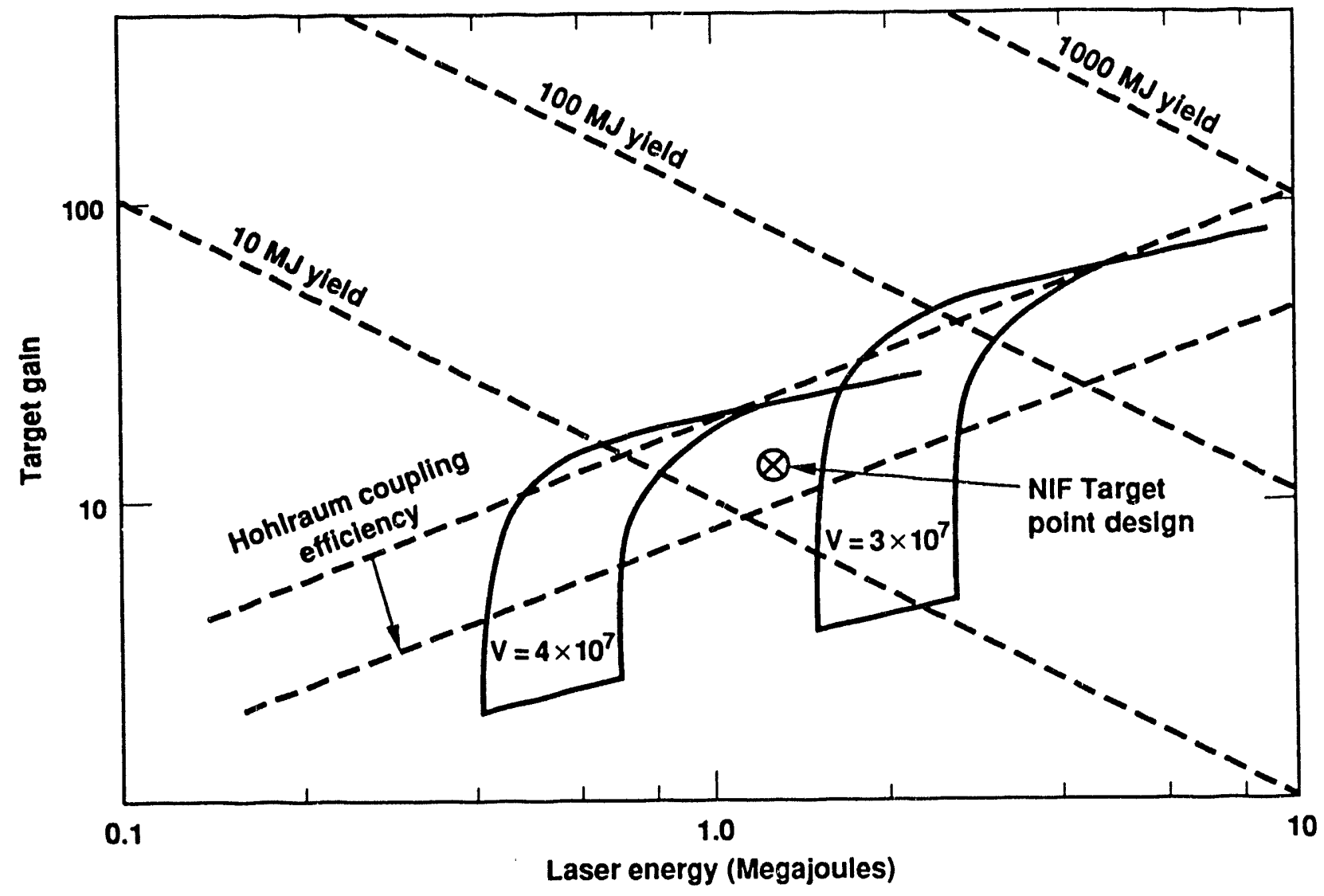

08-00-1093-3691 pub

Fig. 3. The National Ignition Facility (NIF), based on a neodymium glass laser, is being designed to demonstrate ICF capsule ignition and burn propagation.

19DUint 


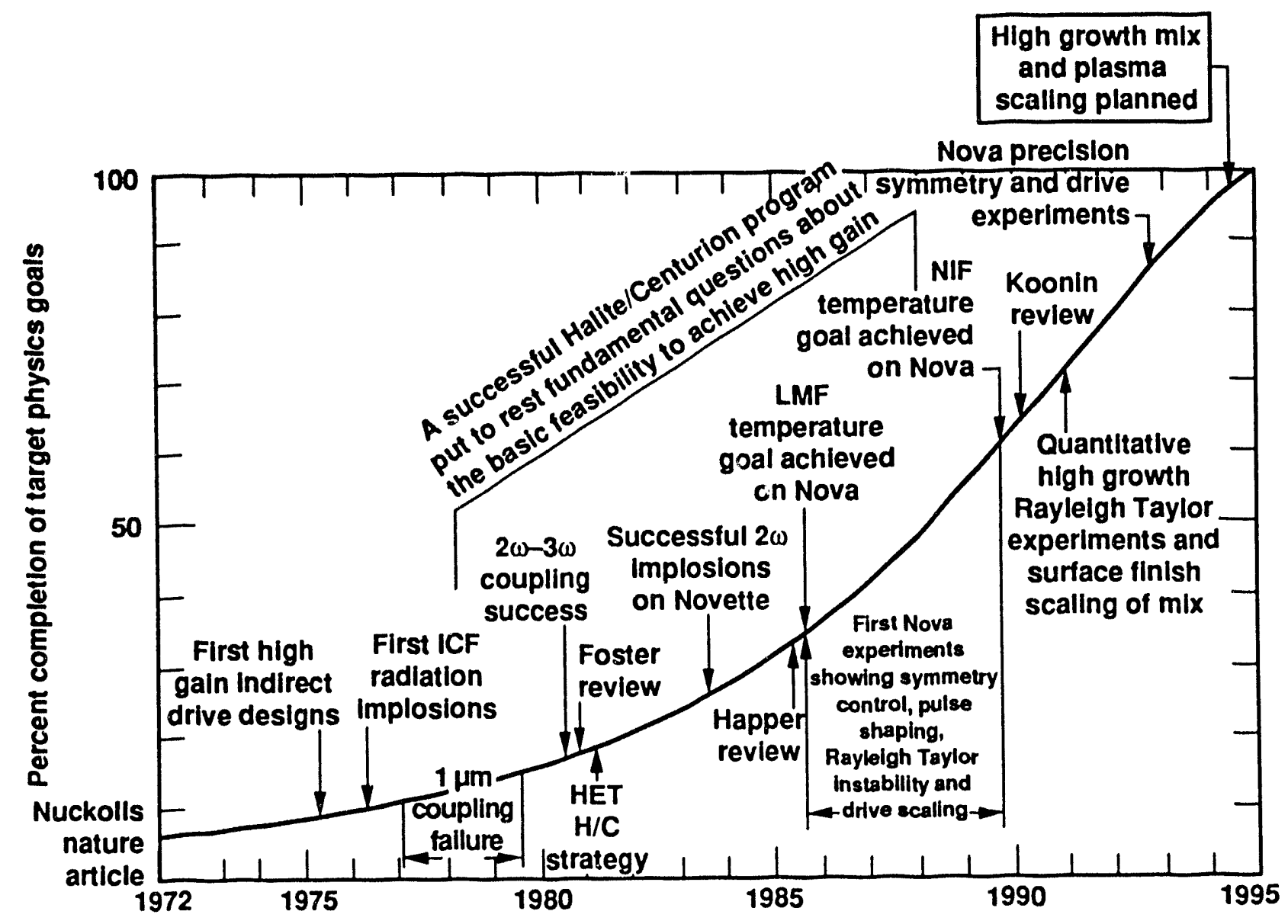

08-00-1093-3688.pub

Fig. 4. We are nearing completion of a two decade effort to develop the data and numerical modeling capability required to accurately specify the requirements for ignition and high gain ICF targets. 


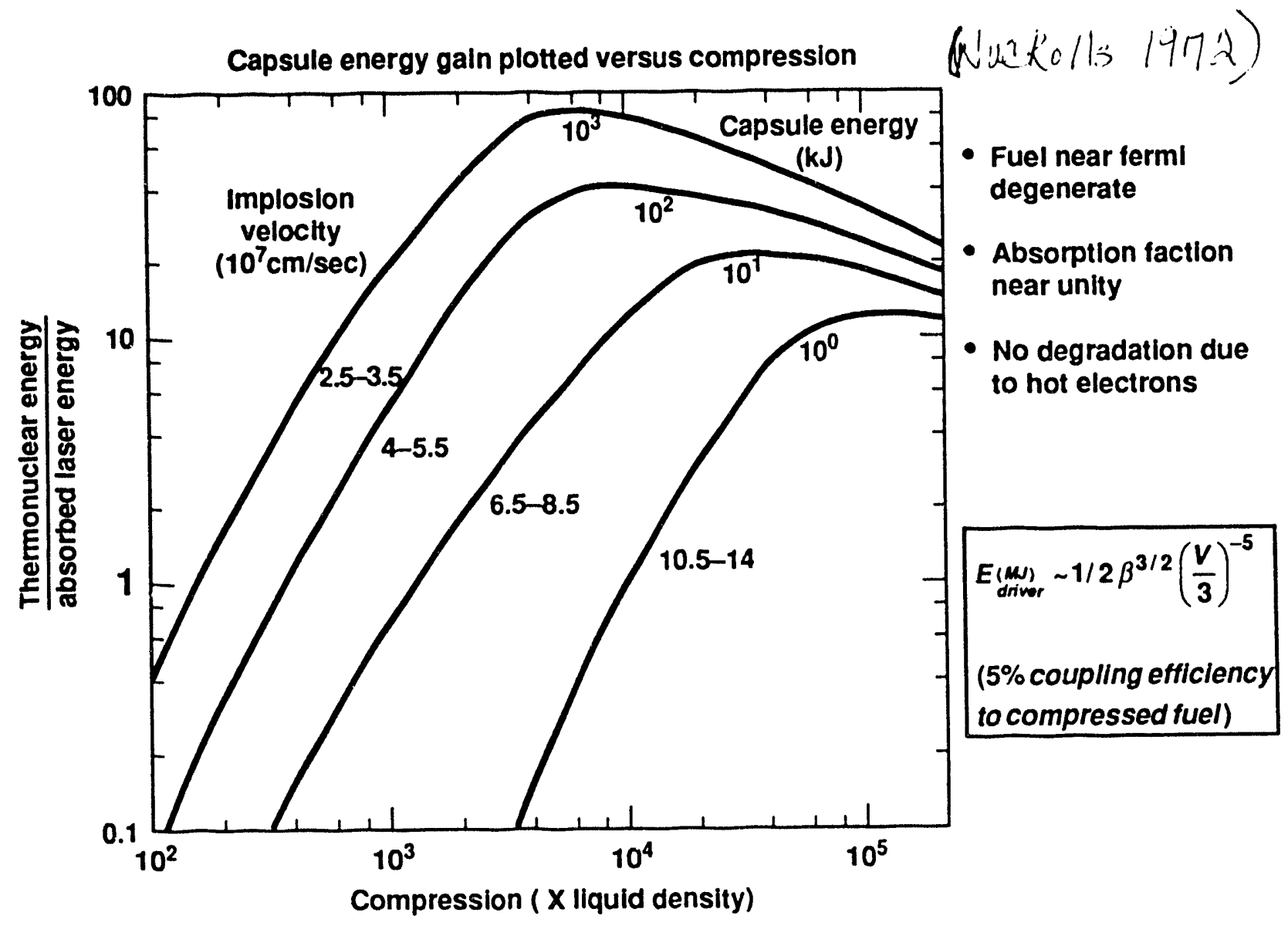

$08 \cdot 00-1093-3621$ put

Fig. 5. The initial capsule energy estimates for ICF could be met with a factor of 3-4 increase in the achievable implosion velocity compared to velocities predicted for the NIF. 


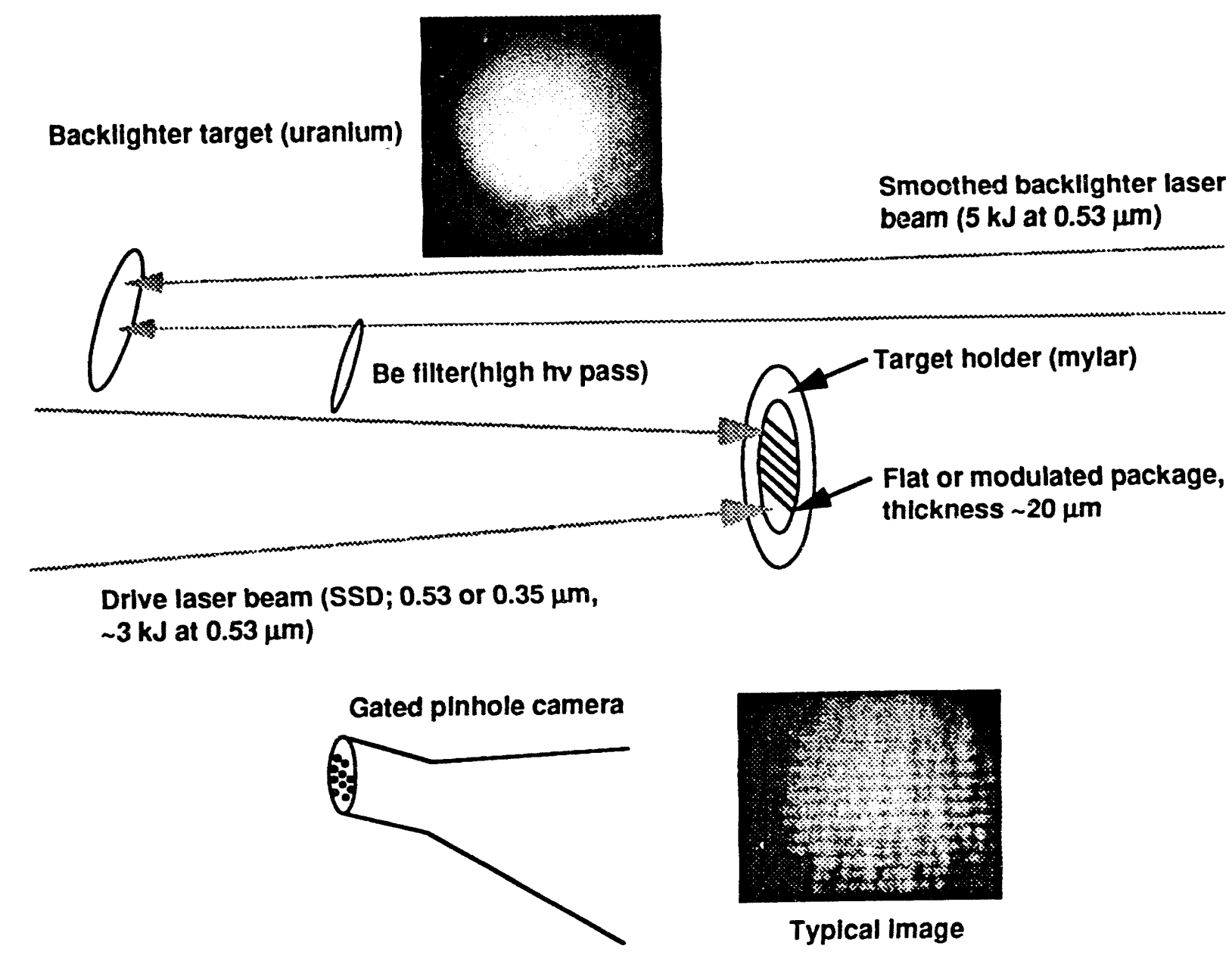

20-03-0893-3054.pub

Fig. 6. Planar direct drive Rayleigh-Taylor experiments have been carried out on the Nova laser.

20scamt 

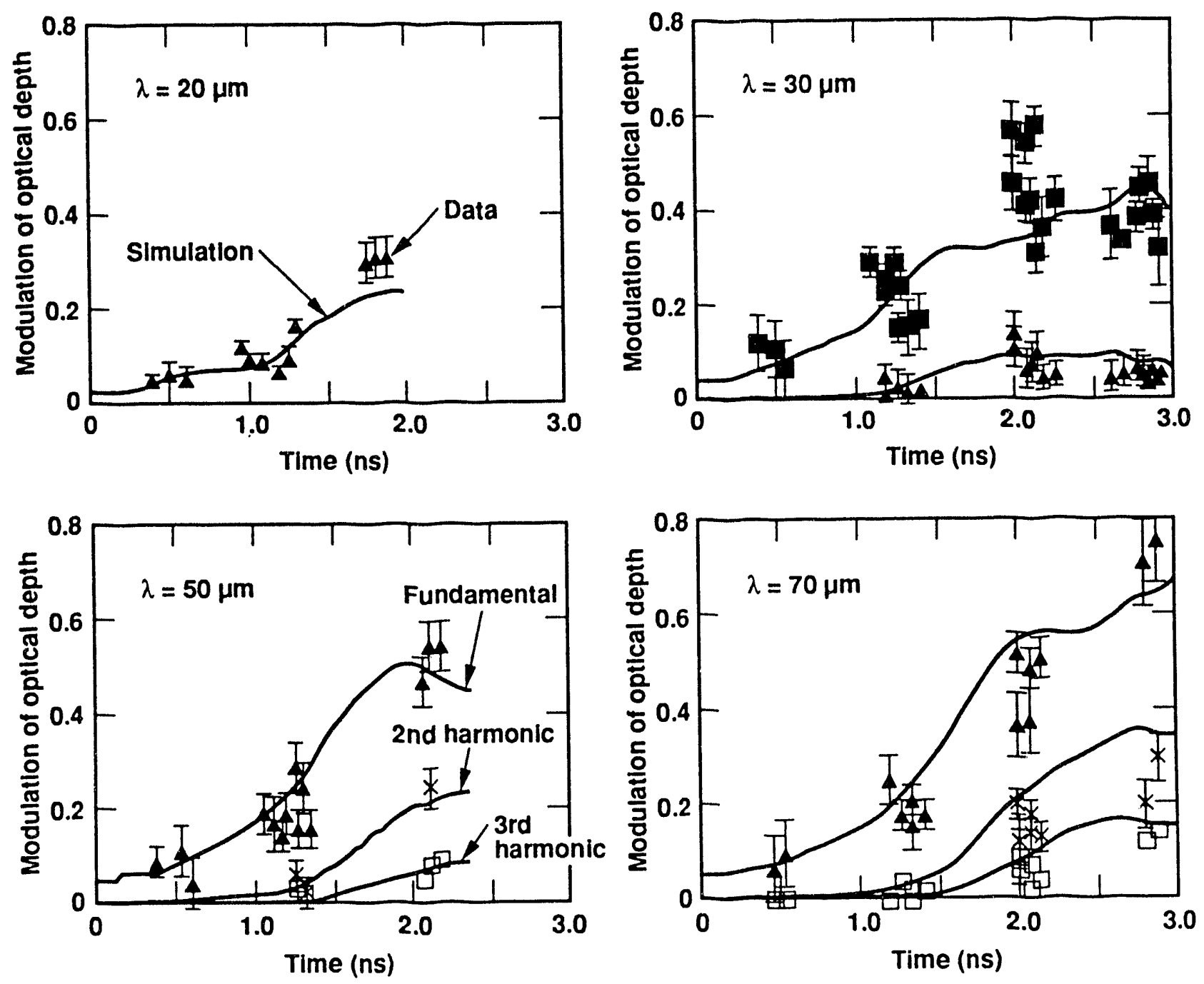

2003-0893-3056.pub

Fig. 7. Experimental data agree with predictions at all harmonics and wavelengths studied $\left(a_{0}=1.0, m\right)$. 20SGG/Wh 


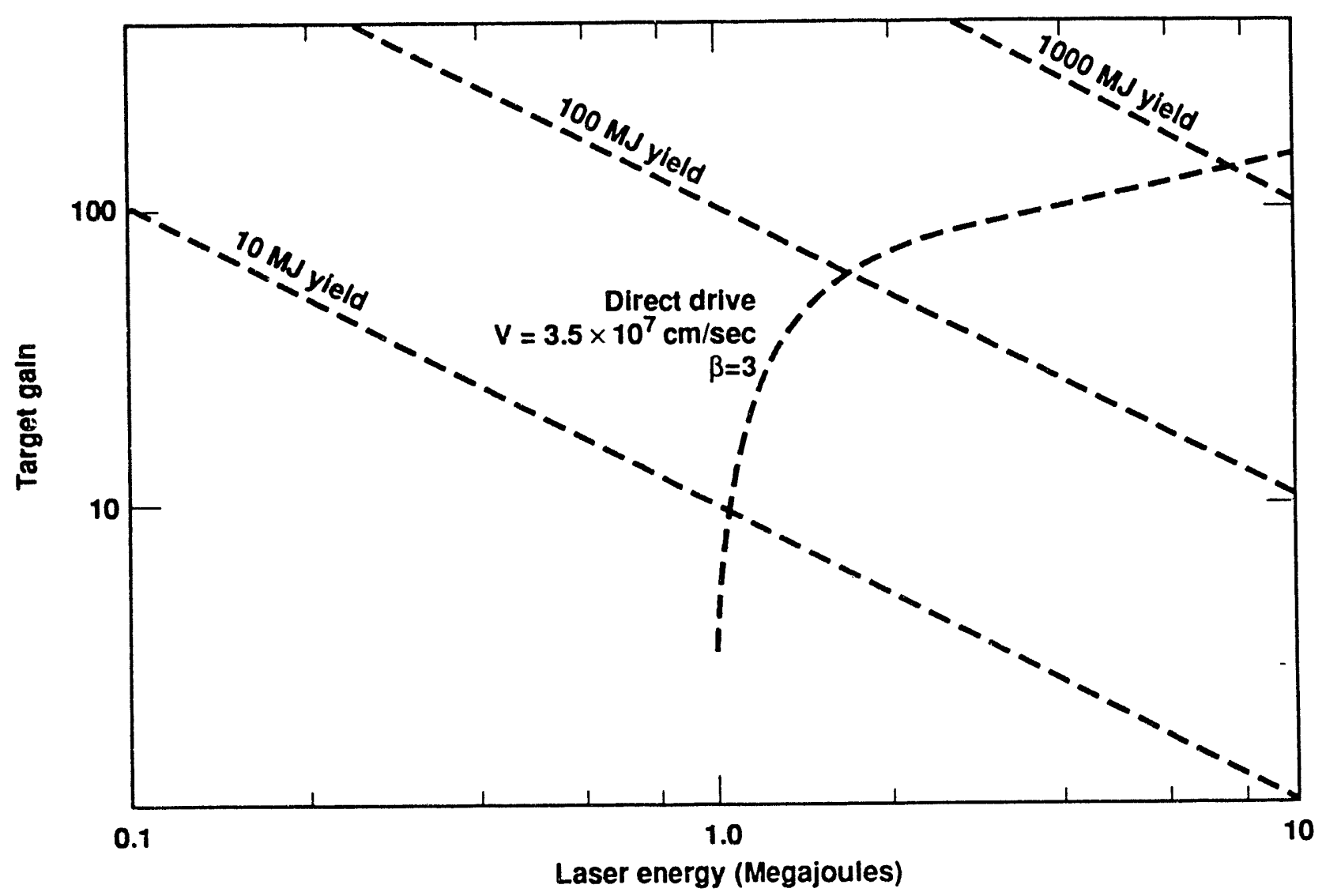

$0800-1093-3617$ pub

Fig. 8. Calculations f which constrain Rayleigh-Taylor growth to 6-7 e-foldings predict about a $1 \mathrm{M}$ ] threshold laser energy for direct drive.

$130 \mathrm{Ounth}$ 
Data

\section{Face-on: streaked}

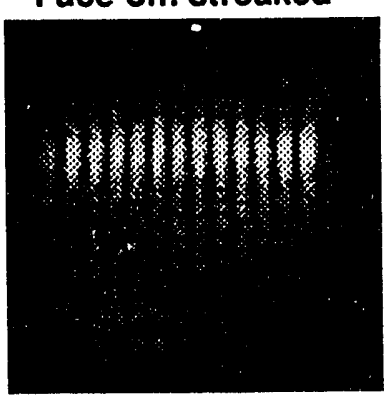

$x$-ay 8.
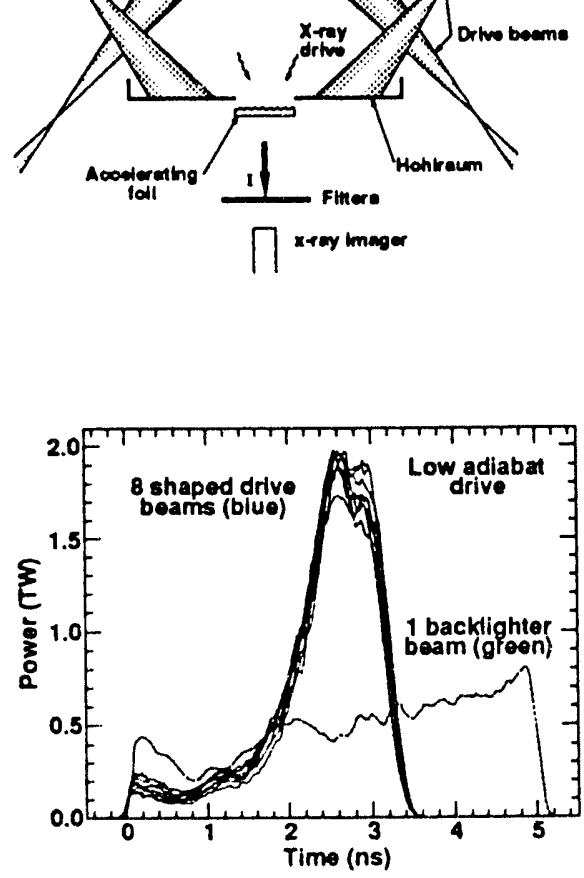

A direct drive LLNL-LLE collaborative program is also underway
Side-on: gated

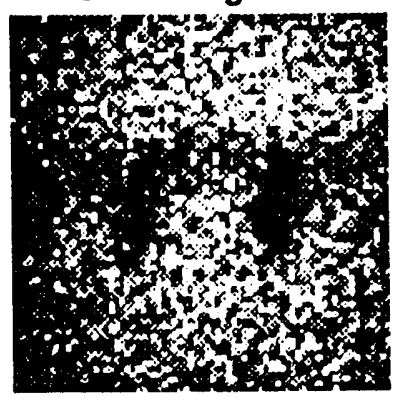

Side-on: streaked

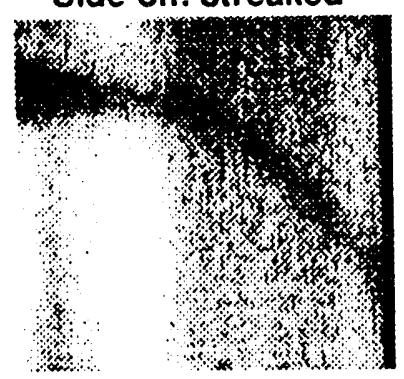

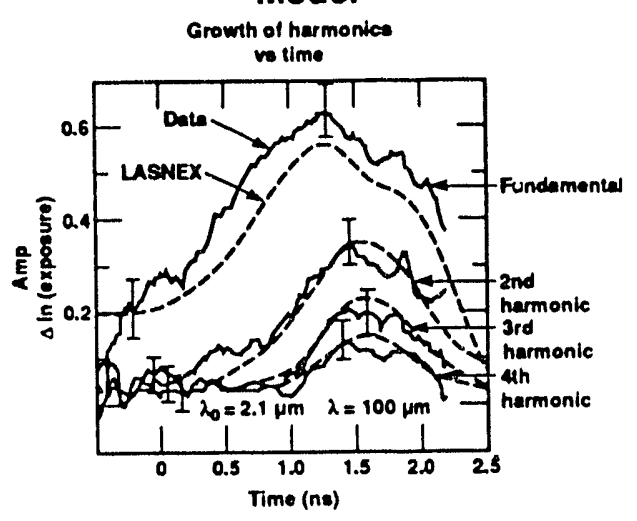

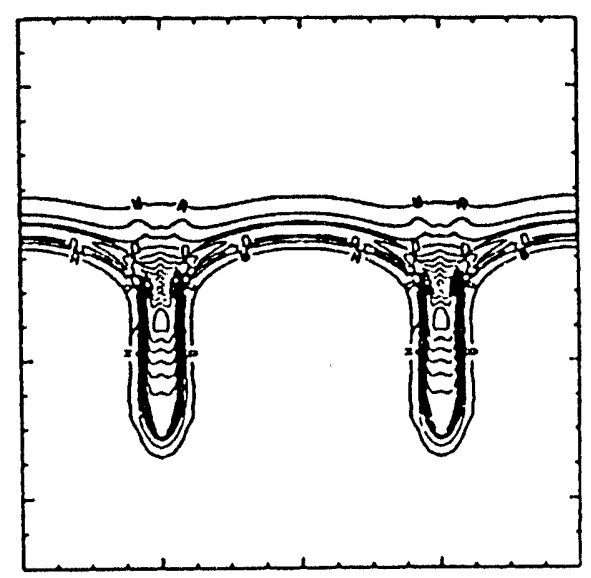

Time (ns)

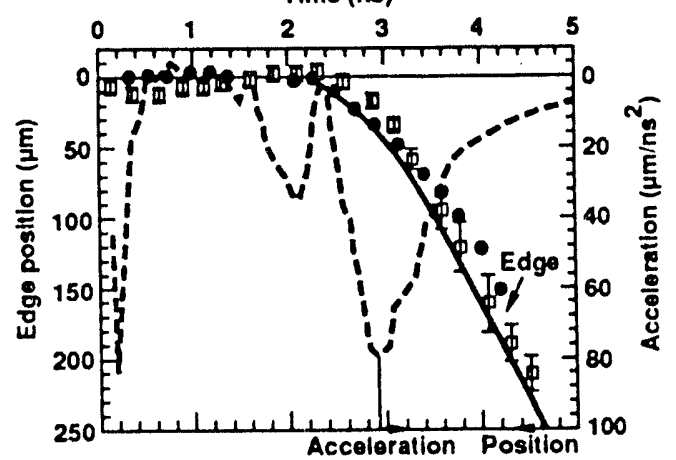

$08-00-0593 \cdot 1818$ pub

Fig. 9. Outstanding progress has been made in the HEP program.

17JDLnwh 


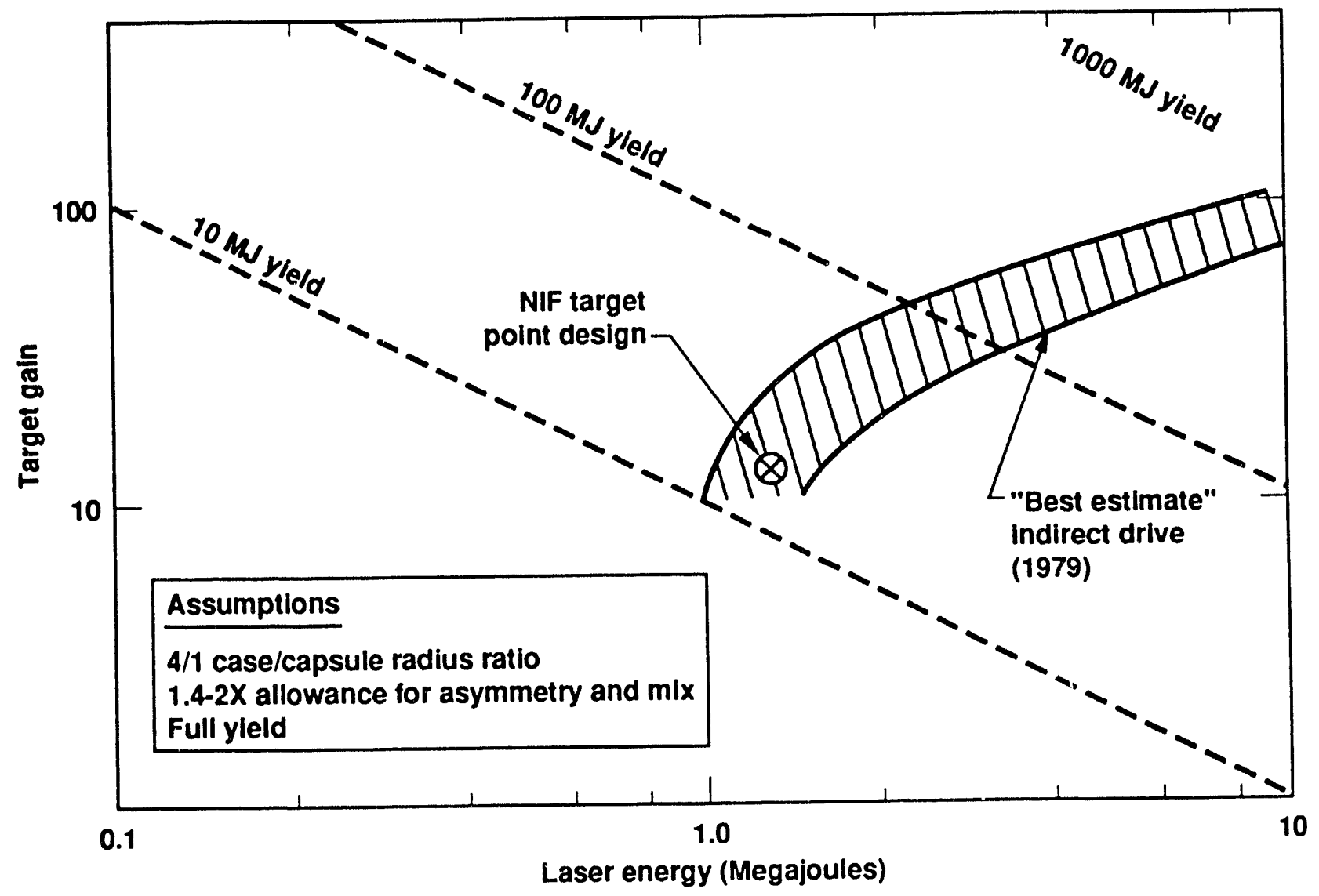

08-00-1093-3618.put

Fig. 10. By 1979 "best estimate" gains for single shell radiation driven targets were comparable to today's estimates.

13 JOUnm 
X-ray Imaging of the Imploded capsules confirm that standard Nova hohlraums provide symmetric radiation drive of the capsule

Standard Nova hohlraums are tuned to produce symmetric drive

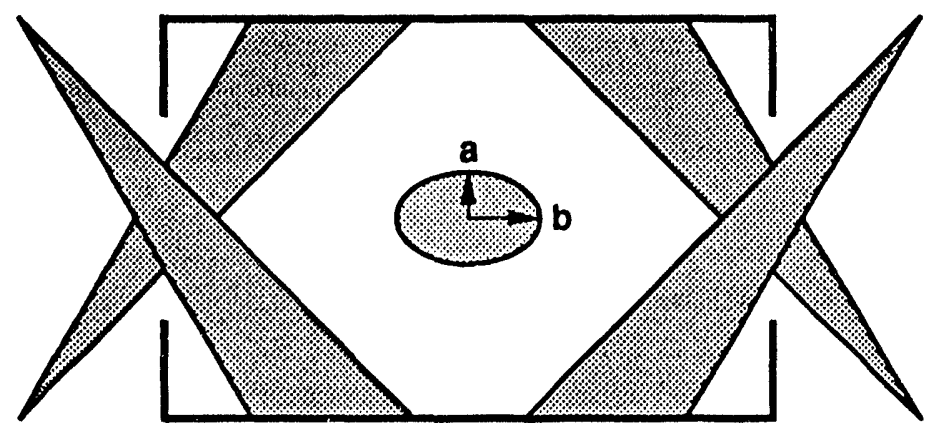

We use distortion $(\mathrm{a} / \mathrm{b})$ as our measure of image distortion In detuned hohlraums

We have systematically detuned the symmetry by varying the laser beam pointing and monitored changes in the capsule image shapes to test our understanding of implosion symmetry

Outward pointing shifts produce "pancake" distortion

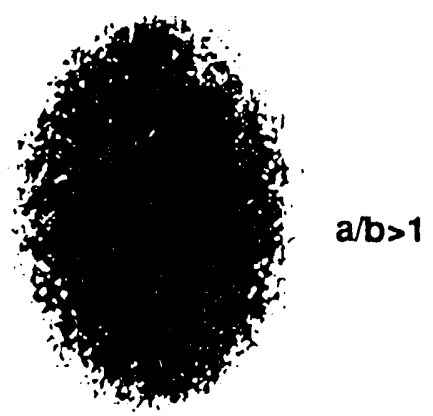

Symmetric

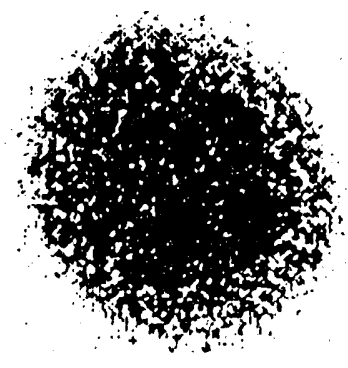

Inward pointing shifts produce "sausage" distortion

Observed X-ray Image shapes confirm the calculated variation of the implosion shape with beam pointing*

08-00-0593-1787A.pub

Fig. 11. We have used $x$-ray imaging of imploding capsules to test our modeling of hohlraum drive asymmetries.

14 JDUwh 

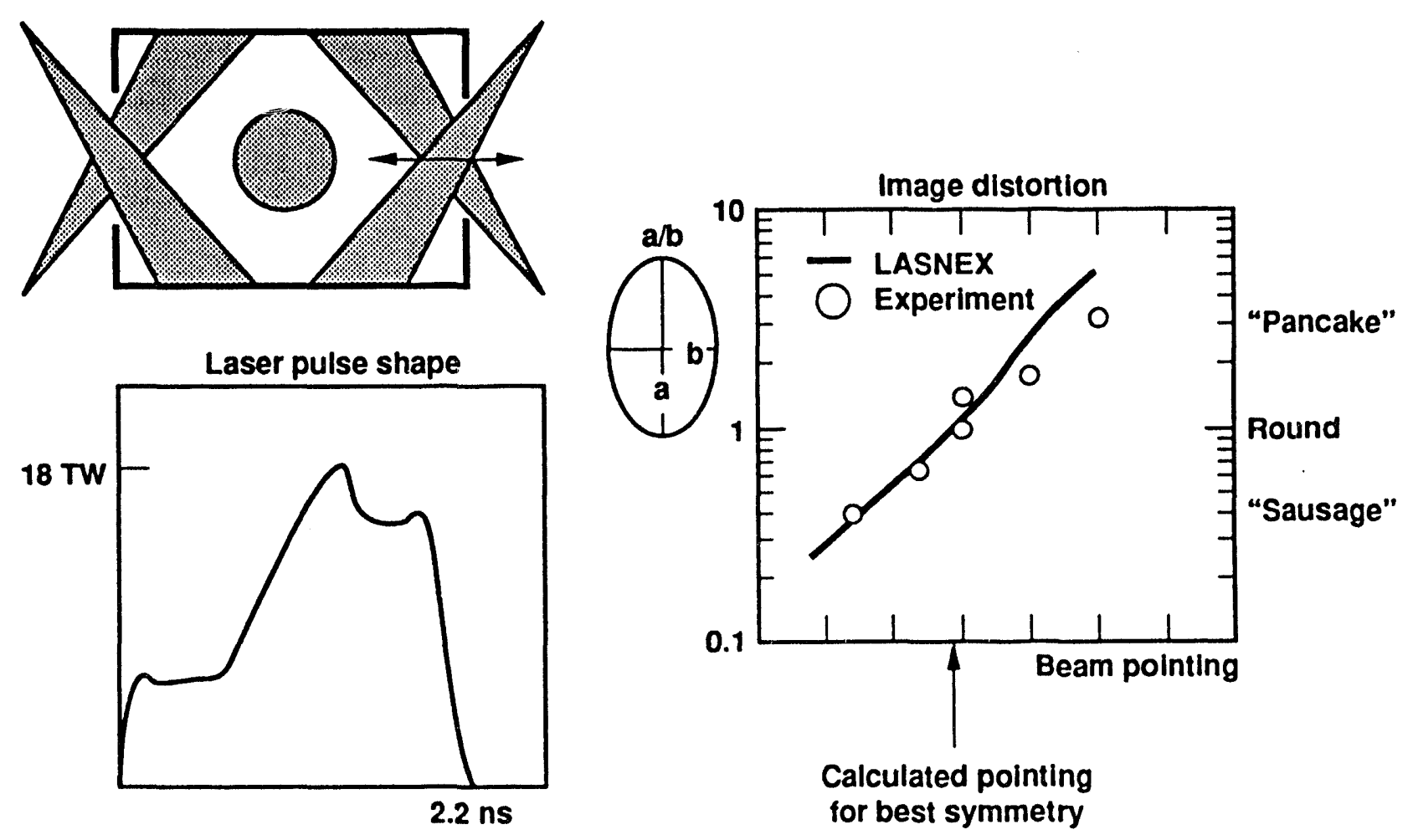

08-00-1093-3848.pub

Fig. 12. We are able to accurately model capsule distortion as a function of beam pointing. 25JOUnm 


\section{We have shown that our implosions are highly reproducible}

\section{Results from recent "precision Nova" experiments}

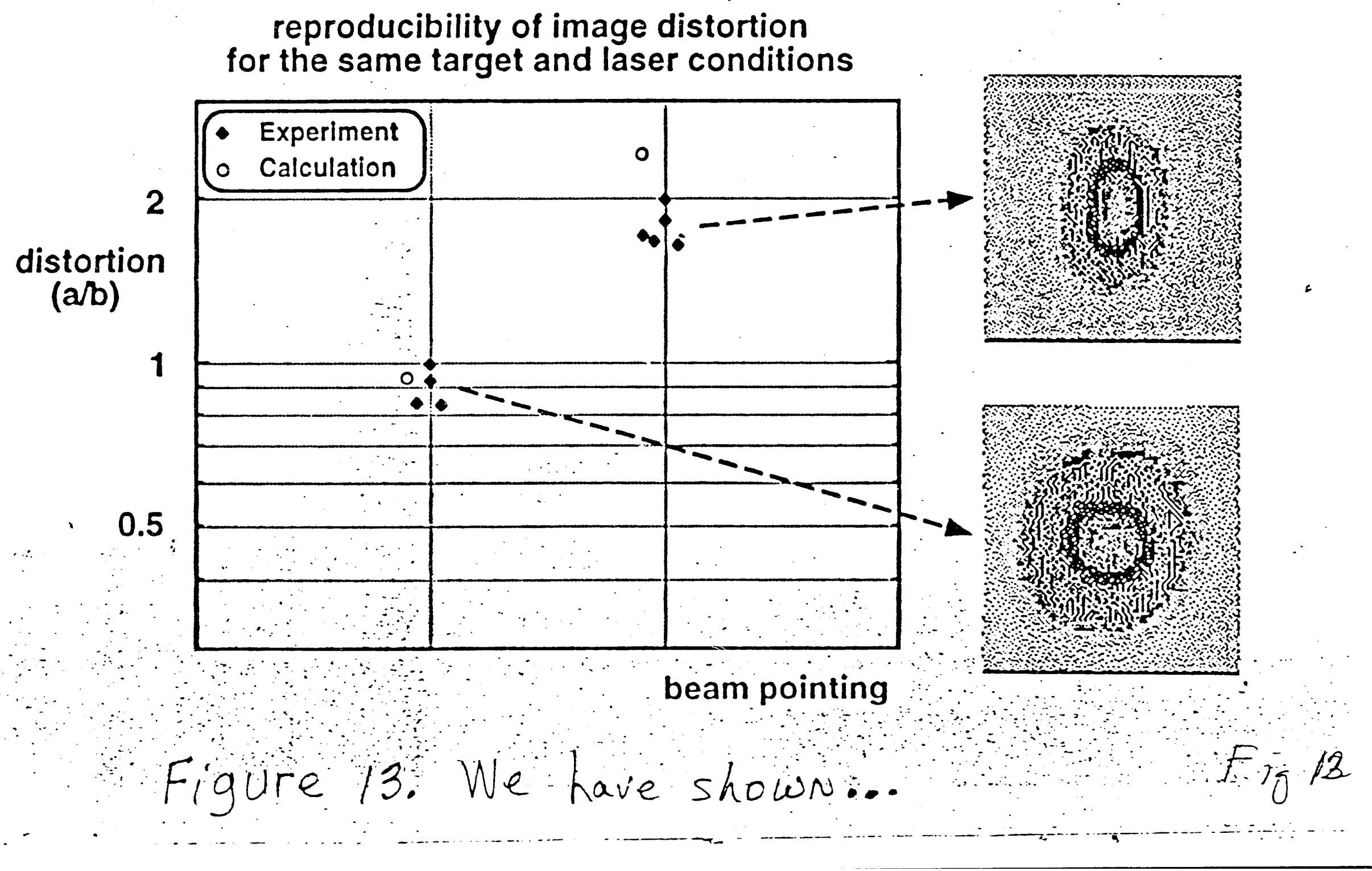




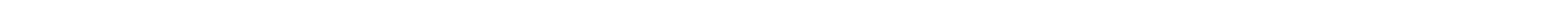


.

.

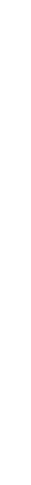

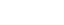

